\title{
Data revisions and the identification of monetary
}

\author{
policy shocks*
}

\author{
Dean Croushore ${ }^{\dagger} \quad$ Charles L. Evans ${ }^{\ddagger}$
}

December 21, 1999

Preliminary and Incomplete

\begin{abstract}
Monetary policy research using time series methods has been criticized for using more information than the Federal Reserve had available in setting policy. To quantify the role of this criticism, we propose a method to estimate a VAR with real-time data while accounting for the latent nature of many economic variables, such as output. Our estimated monetary policy shocks are closely correlated with a typically estimated measure. The impulse response functions are broadly similar across the methods. Our evidence suggests that the use of revised data in VAR analyses of monetary policy shocks may not be a serious limitation.
\end{abstract}

*We thank Jim Sherma for valuable research assistance. This paper represents the views of the authors and should not be interpreted as reflecting the views of the Federal Reserve Banks of Chicago or Philadelphia.

${ }^{\dagger}$ Federal Reserve Bank of Philadelphia; Research Department; Philadelphia, PA; (215) 574-3809; dean.croushore@phil.frb.org

"Federal Reserve Bank of Chicago; Research Department, P.O. Box 834, Chicago, IL 60690; (312) 3225812; cevans@frbchi.org 


\section{Introduction}

Empirical research with vector autoregressions (VARs) typically ignores issues associated with data revisions and economic agents' access to only real-time data releases. An example of this is the literature on monetary policy shocks in VARs (for example, Bernanke and Blinder (1992), Sims (1992), Christiano, Eichenbaum and Evans (1996, 1999), Sims and Zha (1996) and Bernanke and Mihov (1998)). Each of these studies is based upon some data series that were not known to anyone during the period of the empirical analysis. Specifically, the data used in these studies, and other macroeconomic time series research, have been revised relative to the data known at that time. Since government agencies and private sources do not provide these data conveniently, these shortcuts are rarely even questioned. ${ }^{1}$ The realtime data collected by Croushore and Stark (1999), however, allows researchers to explore the empirical robustness of many existing macroeconomic results to this issue. Armed with the original data releases that were known at that time to business analysts, market participants, policymakers, and the rest of the interested universe, the econometrician can quantify, how much of a difference does this make to empirical analyses of monetary policy shocks?

Addressing this question is complicated by the fact that some data are always revised, and hence the true underlying economic concept is never observed fully. For example, aggregate economic activity in the United States is not directly observable, but data on real GDP is reported and revised by the Bureau of Economic Analysis. The monetary policy shock literature has focused on how real GDP (for example) is affected by an exogenous shock to monetary policy. This is an interesting question when real GDP is taken to be an accurate measure of aggregate economic activity, but the focus should instead be on the impact of monetary policy shocks on economic activity. Consequently, when data revisions are accounted for in empirical VAR analyses, the unobserved true variable must be modeled. ${ }^{2}$ In standard $O L S$ estimates of autoregressions, this will induce errors-in-variables biases.

Errors-in-variables issues raise another econometric problem for identified VAR analyses,

\footnotetext{
${ }^{1}$ Diebold and Rudebusch (1991) investigate this issue for the index of leading indicators. Rudebusch (1998) criticizes VAR-based estimates of monetary policy reaction functions for ignoring this issue. Orphanides (1998) empirically assesses the importance of this issue for Taylor rule estimates.

${ }^{2}$ Sargent and Sims (1977) provide an early example of this environment. Sargent (1989) and Stock and Watson (1989) discuss how Kalman filter methods can be used tractably to estimate these models.
} 
not simply the literature on monetary policy. Structural shocks are identified based upon the covariance structure of the VAR innovations. The standard method of estimating VAR innovations from the residuals, however, will include data revisions (or measurement noises). In general, the revision components will be correlated across the equations in the system. Identifying the economic shocks from the measurement noises requires more structure on the measurement process. In our empirical example, conditional on having the complete data set, the identification and estimation of the monetary policy equation is simpler than the other nonpolicy, nonfinancial, and non-auction price equations.

This paper considers two approaches to addressing the fact that econometricians' macroeconomic data sets are changing over time due to data revisions. The first approach is to assess the sensitivity of VAR estimates across different data vintages. For example, how do monetary policy reaction function estimates change when the sample period is fixed at 1960-1983, but the data vintages are updated every year? This analysis does not explicitly consider how the data revision process takes place. The second approach considers a statistical model of data revisions and implements an alternative, real-time estimation strategy to overcome the errors-in-variables biases. Our method assumes that output, the price level, and monetary aggregates are latent variables that the data collection agency never measures precisely. Given a standard set of restrictions to identify policy and nonpolicy shocks in the absence of measurement noises, our analysis with these noises is able to identify the shocks and compute impulse responses.

Our empirical analysis of the Christiano, Eichenbaum, and Evans (1996) system suggests that many results from the VAR literature on monetary policy are robust to these issues of real-time data availability. Specifically, our analysis of the 1960-83 estimation period using alternative data vintages (Section 3) uncovers only minor differences in monetary policy shock measures and impulse responses. Our real-time analysis of the 1968-93 period (Section 5) also finds only small differences in the estimated policy shocks between the realtime estimates and 1998-vintage estimates. The estimated effects of monetary policy shocks on variables in the system are somewhat smaller in the real-time system, but qualitatitvely are remarkably similar. ${ }^{3}$ The estimated effects of other orthogonalized shocks are also similar

\footnotetext{
${ }^{3}$ We have not computed measures of uncertainty associated with these responses at this stage of our
} 
in the real-time system for the first three to five years of responses. After this length of time, the price variables in the real-time system exhibit trending behavior, while the 1998-vintage responses seem to revert to zero.

The paper is organized as follows. Section 2 discusses the relationship between the VAR literature on monetary policy and real-time information sets. Section 3 investigates the robustness of two VAR studies to using alternative data vintages in the estimation over the period 1960-83. Section 4 discusses difficulties raised by real-time data issues in an example, two-variable autoregression; and proposes an estimation strategy. Section 5 reports empirical results for this method applied to the Christiano, Eichenbaum, and Evans (1996) system. Section 6 concludes.

\section{The literature and real-time data issues}

The empirical literature that quantifies the effects of exogenous monetary policy shocks on the economy proceeds along the following lines. The monetary authority has a policy instrument $S_{t}$ which is set as a function of the state of the economy. A general specification of the Fed reaction function is

$$
S_{t}=f\left(\Omega_{t}\right)+\varepsilon_{t}
$$

where $\Omega_{t}$ is the Fed's information set at time $t$ and $\varepsilon_{t}$ is an exogenous shock. This specification is embedded in the approaches of Galí (1992); Bernanke and Blinder (1992); Christiano, Eichenbaum, and Evans (1996, 1999); Sims and Zha (1996); Leeper, Sims and Zha (1997); and Bernanke and Mihov (1998). The points of departure in these studies are the choices of the policy instrument $S_{t}$, the variables included in the information set $\Omega_{t}$, as well as the different functions $f(\cdot)$, and the correlation structure between the exogenous shock $\varepsilon_{t}$ and the information set $\Omega_{t}$.

A common approach in these studies, however, is the use of a macroeconomic data set that was not consistently available during the entire period of the analysis. Each study uses a data set whose variables have been revised over time, following the original data release.

research. 
For example, Christiano, Eichenbaum, and Evans (1996) use a data set that was collected in mid-1993 and included real GDP data through the fourth quarter of 1992. Although the real GDP data for 1992:Q4 had only been revised twice (no benchmark revision), the historical data going back through 1960 had been revised many times. As we noted in the introduction, the empirical VAR literature has neglected the effects of data revisions. ${ }^{4}$ This omission is apparent in the monetary policy rule (2.1) since it does not reflect the vintage of the data in the information set. Let $T$ reflect the date of the data set's construction by the econometrician. Period $T$ will often be the final observation in the data set, although this does not need to be the case. In this setting, the empirical policy rule in the existing literature should be restated as

$$
S_{t}^{T}=f\left(\Omega_{t}^{T}\right)+\varepsilon_{t}^{T}
$$

One reaction to this criticism is to estimate $f(\cdot)$ using $\Omega_{t}^{T_{j}}$ for various data vintages $T_{j}$ to see if the estimates differ, while holding the full-sample period fixed. Using this approach, we provide evidence on the robustness of two VAR studies in section 3 (Christiano, Eichenbaum, and Evans (1996) and Galí (1992)).

A further criticism of most macroeconomic, time series studies is that the data contained in $\Omega_{t}^{T}$ for $t<T$ were not known at time $t$. In most cases, the data have been revised $;^{5}$ this critique also holds for the approach using $\Omega_{t}^{T_{j}}$. Consequently, even with certain knowledge of $f(\cdot), \varepsilon_{t}^{T}$ will differ from the true policy shock (see Rudebusch 1998 and Christiano, Eichenbaum, and Evans 1999). Assuming that the monetary authority uses a time-invariant function $f(\cdot)$ to set the policy instrument, the reaction function is

$$
S_{t}^{t}=f\left(\Omega_{t}^{t}\right)+\varepsilon_{t}
$$

The notation with superscript $t$ here indicates that the monetary authority sets the policy instrument $S_{t}$ on the basis of information that is actually available to it during period $t$.

\footnotetext{
${ }^{4}$ Rudebusch (1998) criticizes the monetary policy shock literature for ignoring this. However, in principle, the problem is pervasive in macroeconomic time series studies generally. See Croushore and Stark (1999) for examples.

${ }^{5}$ Almost all seasonally adjusted, macroeconomic time series data are revised for a substantial period of time.
} 
The conflict between the empirical investigation of monetary policy and the actual setting of policy is troubling in principle. Rudebusch (1998) stresses this conflict, but provides no direct evidence on the economic importance of the issue. To assess the economic consequences of using revised data, three questions emerge. First, how do the empirical policy shock measures and policy instrument settings differ in equations (2.2) and (2.3)? In general, estimating (2.2) using standard VAR methods will not recover the reaction function and policy shocks in (2.3). Second, how are impulse response functions from policy shocks to other macroeconomic data affected by this conflict? This question is far more difficult to assess than the first one. In most cases, computing impulse response functions from a monetary policy shock requires estimating the VAR equations for the other variables. ${ }^{6}$ Although monetary policy may plausibly respond to each new data revision as described in (2.3), this assumption is somewhat more problematic for real $G D P$. Should we really expect that true output will be affected directly by the government's announcement that last month's announced figure for real $G D P$ was half a percentage point too high? Further assumptions about the nonpolicy equations are required: assumptions about the data revision process over time and the information available to economic agents at any point in time. As the discussion in section 4 indicates, the problems posed by data revisions range beyond the monetary policy shock literature. Third, how is the identification of non-monetary policy shocks affected by data revision issues? Simple examples below suggest that VAR innovations estimated using revised data will include revision errors. Since identification of exogenous shocks is achieved by factoring particular covariance matrices of VAR innovations, the presence of additional covariation due to revision errors cannot be ignored, in principle.

\footnotetext{
${ }^{6}$ An exception is the two-step strategy described in Christiano, Eichenbaum, and Evans (1999) for a particular recursively identified policy rule. Although the two-step strategy is asymptotically justifiable for any impulse response function, it does require a time series on the exogenous shock. If the exogenous shock can only be identified with the aid of another variable's innovation, then the other equation must be estimated. The identification strategies of Sims and Zha (1996), Galí (1992), and Bernanke and Mihov (1998) require these additional restrictions.
} 


\section{Monetary policy estimates with different data vintages}

Is there a simple way to see if data revisions really matter for the identification of monetary policy shocks? One way to answer this question is simply to investigate how changes in the vintage of the data affect the size of monetary policy shocks or impulse response functions.

Potentially, this issue could be very important. In examining the robustness of empirical macroeconomic studies, Croushore and Stark (1999) found that some empirical results were strongly affected by data revisions. For example, some of the empirical results of Hall (1978) and Blanchard and Quah (1989) changed dramatically when alternative vintages of data were used. In both cases, the sample period used in the empirical work wasn't changed, only the date on which the data were measured.

To investigate the robustness of VAR results for measuring monetary policy shocks, we use the real-time data set of Croushore and Stark, and rerun the empirical work of Christiano, Eichenbaum, and Evans (1996) and Galí (1992), using the same sample periods as they use, but four alternative vintages of the data. We then examine the degree to which these alternative data sets lead to differing magnitudes for monetary shocks and the impulse responses to monetary shocks. We'll look at data sets that span 15 years. The data, especially NIPA data, have been revised significantly across that span, and thus could potentially have a large impact on the empirical results.

\subsection{Christiano-Eichenbaum-Evans (CEE)}

The benchmark CEE quarterly model consists of a recursively identified VAR in six variables: real output $(\mathrm{Y})$, deflator $(\mathrm{P})$, nonborrowed reserves $(\mathrm{NBR})$, federal funds rate $(\mathrm{FF})$, total reserves (TR), and commodity prices (PCOM), where $\mathrm{Y}, \mathrm{P}, \mathrm{NBR}$, and TR are in logs. Using the Choleski decomposition, the causal ordering of the variables is important, and we use the CEE benchmark ordering Y, P, PCOM, FF, NBR, TR in everything that follows.

Our real-time data set includes the values of all six variables as they existed in macroeconomic data sets in the fourth quarter of each of the following years: 1983, 1988, 1993, and 1998. The federal funds rate and commodity price variables aren't revised, but the other four variables were revised substantially over this time period, including such major revisions 
as switching from GNP to GDP, and changing from fixed-weight real output and deflator to chain weighting. We maintain a common sample period for all four vintages of data, using just data from the sample that's common to all four data sets, 1960Q1 to 1983Q3.

The VAR is estimated and the monetary policy shocks are taken to be the orthogonalized innovations from the federal funds rate equation. Figure 3.1 illustrates the shocks that we estimate, with each of the four different lines corresponding to a different vintage data set.

The figure shows that the measured monetary policy shocks differ somewhat in magnitude across the alternative data vintages, but they are qualitatively very similar. In almost every case, the shocks are of the same sign across vintages and display the same timing in terms of peaks and troughs. In a few cases, they are opposite in sign, as in early 1972. In other cases, as near the end of the sample period, the last data points are quite a bit different quantitatively in the 1983 vintage data set. But this is as you might expect, given that the data points at the end of the sample in the 1983 vintage data set haven't been revised at all, and thus don't incorporate important source data that are used in all the other vintage data sets.

Looking at the impulse response functions (Figure 3.2) yields a similar result-there are very few differences across vintages of the data. The only case in which the vintage matters significantly is the response of prices. In the earliest vintage data set (1983), the price puzzle takes much longer to resolve than with other vintages. In all four vintages, the long-run effect is a decline in prices, but the long-run effect is greater, the later the vintage. This suggests that the impulse responses may be somewhat sensitive to data revisions. However, the variable itself has also changed over time, from GNP deflator, to GDP fixed-weight deflator, to GDP chain-weight price index.

\subsection{Galí}

The CEE model is a straight VAR with no economic structure. But much recent empirical work has used economic theory to impose structure on the VAR, using short-run and long-

run restrictions to provide identification. One such model is that of Galí (1992). The Galí model is a VAR in four variables, with the growth rate of real output (Y), the quarterly change in the interest rate $(\mathrm{FF})$, the real interest rate, which equals the interest rate minus 
the quarterly inflation rate in the consumer price index $(\mathrm{P})$, and the growth rate of the real money supply (MONEY), which equals the log of the nominal money supply minus the log of the price level. The only difference between our data and Galí's is that we use the federal funds rate, while he used the interest rate on three-month T-bills, but that difference should matter little for the empirical results.

Imposing identifying restrictions on the VAR allows one to calculate structural shocks and to generate impulse response functions. Galí imposes three long-run restrictions on the VAR: money supply shocks don't affect output, money demand shocks don't affect output, and spending shocks don't affect output. He also imposes three short-run restrictions: money supply shocks don't affect output contemporaneously, money demand shocks don't affect output contemporaneously, and the price level doesn't enter the money supply equation contemporaneously.

The shocks to monetary policy, shown in Figure 3.3, are again quite similar across vintages of the data. The only surprise is that the 1988 vintage of the data shows somewhat larger shocks than the other three vintages. But the timing of all the shocks is identical; they differ only in magnitude.

The impulse responses in the Galí model, shown in Figure 3.4, differ a bit across vintages as well. Again, though, they are qualitatively the same in terms of their general paths. The revisions seem to affect the impulse response to real money balances the most.

Had the measures of monetary policy shocks and the impulse response functions across these four vintages been dramatically different, the robustness of VAR methods for measuring monetary shocks might have been in doubt. The results from these two models, however, don't suggest that data revisions are terribly problematic for measuring monetary shocks. But the quantitative differences across vintages are enough to make us want to investigate more carefully the effect of data revisions on these empirical methods. To that end, we now examine the revision process more carefully, and see how VAR estimates may be affected by different types of revisions to the data. 


\section{Estimating a VAR with real-time data}

To investigate the influence of real-time data issues for estimating VARs, we specify a twovariable, recursively identified example and impose structure on the data revision process. The methods adopted here for estimating and analyzing the two-variable system extend easily to higher order systems. The VAR includes two distinct types of variables. The first type is financial data, like the federal funds rate $(F F)$, that are set on the basis of real-time data and do not get revised. The second data type is revised over time, like real GDP $(Y)$ : its timeseries law of motion is specified in terms of an underlying, latent variable that is measured imperfectly. ${ }^{7}$ In one respect, the real-time policy and financial variable equations are the simplest to estimate: given the actual real-time data, these equations can be estimated by ordinary least squares. By placing sufficient structure on the historical data revision process, we deduce an instrumental variables estimation strategy for the nonpolicy/financial equations.

\subsection{A recursively identified VAR}

In this example, we take the true data-generating process to be a two-equation identified VAR. The monetary authority sets the federal funds rate $F F_{t}$ on the basis of its own past history, and the data reported for $Y$ at time $t$. We will refer to $Y$ as output, but it can just as easily be a vector of data. The law of motion for the true, unobserved output series $Y_{t}^{*}$ is distinct from the data reporting process. The system of equations is:

$$
\begin{aligned}
F F_{t} & =A_{F F}(L) F F_{t-1}+A_{Y}(L) Y_{t-1}^{t}+a_{Y} Y_{t}^{t}+\varepsilon_{1 t} \\
Y_{t}^{*} & =B_{F F}(L) F F_{t-1}+B_{Y}(L) Y_{t-1}^{*}+\varepsilon_{2 t}
\end{aligned}
$$

Specifying the policy reaction function in real time requires explicit assumptions about the way data revisions influence policy. Equation $(4.1 a)$ is based upon data known at time $t$,

\footnotetext{
${ }^{7}$ Relative to our earlier $C E E$ system, this category includes $Y, P, N B R$, and $T R$. Although commodity prices would seem to naturally fit into the first category, alternative informational assumptions may better place them in the second category.
} 
namely, $Y_{t}^{t} ; F F_{t-1}, Y_{t-1}^{t} ; F F_{t-2}, Y_{t-2}^{t}, ;$ etc. $^{8}$ Equation (4.1a) makes a strong assumption: $F F$ will respond systematically to changes in the reported data even when the underlying $Y^{*}$ does not change. Of course, $Y^{*}$ is not directly observed, so there is no contradiction.

Equation $(4.1 b)$ is the law of motion for $Y_{t}^{*}$ and has two features worth noting. First, the data revisions influence $Y^{*}$ indirectly through their effects on $F F$ and monetary policy. Second but more critical, the latent variable $Y^{*}$ depends upon its own history and not directly on the history of real-time data releases. This relationship might emerge in an economy where agents see the true economic allocations, while the monetary authority sees only error-ridden measures. Although this is a questionable assumption, the alternatives may not be much better. This is a questionable assumption given the enormous efforts that central banks expend to measure and understand the state of their economies each period. Considering the fact that the Federal Reserve already purchases certain types of financial data from private companies, they would clearly pay to observe $Y_{t}^{*}$ if private agents actually knew that information. An alternative line of reasoning might assume that no one in the economy observes $Y^{*}$. This could be accommodated by also including $\left\{Y_{t-s}^{t}, s \geq 0\right\}$ in equation $(4.1 b)$, or simply its revisions. In this case, however, it is difficult to think about state-contingent allocations, market-clearing, or prices. This approach is worth investigation, but has not been pursued here.

This system of equations is written as a recursively identified VAR, with the $\varepsilon_{1 t}$ and $\varepsilon_{2 t}$ shocks assumed to be exogenous, and uncorrelated with the other right-hand-side variables. The vector of exogenous shocks $\varepsilon_{t}=\left(\begin{array}{ll}\varepsilon_{1 t} & \varepsilon_{2 t}\end{array}\right)^{\prime}$ has a diagonal covariance structure.

Each period the output data are revised. The data revision process has the following form: ${ }^{9}$

$$
\begin{aligned}
Y_{t}^{t} & =Y_{t}^{*}-g_{t}^{*} \\
Y_{t}^{t+s} & =Y_{t}^{t+s-1}+h_{t}^{t+s}, \quad \forall s>0, \quad \forall t \\
Y_{t}^{*} & =Y_{t}^{T}+h_{t}^{T *}, \quad T=\text { latest release date. }
\end{aligned}
$$

\footnotetext{
${ }^{8}$ Superscripts refer to the reporting vintage of the data, while subscripts refer to the observation period. Notice that the lag operator $L$ operates on the observation date only, and not the data's vintage date.

${ }^{9}$ Our data are measured in natural logarithms for our VAR estimation, except for $F F$. Consequently, we need to assume that these revisions take place with respect to the log of the series.
} 


$$
g_{t}^{*}=h_{t}^{t+1}+h_{t}^{t+2}+\ldots+h_{t}^{T}+h_{t}^{T *}
$$

The initial data release is $Y_{t}^{t}$, and equation (4.2a) indicates that $Y_{t}^{t}$ is an imperfect measure of $Y_{t}^{*}$, given the error term $g_{t}^{*}$. Each period $t+s$, the previously released data are revised by $h_{t}^{t+s}$ according to (4.2b). Equation (4.2c) specifies how the latest data release $Y_{t}^{T}$ is also an imperfect measure of the unobserved, true output variable $Y_{t}^{*}$. This specification readily admits further analysis with a later data release $Y^{T+1}$, and thus captures the notion that $h_{t}^{T *}$ represents a permanent wedge between measuring and observing true output $Y_{t}^{*}$. Although we do not specifically restrict the revision process $h_{t}^{t+s}$, equation (4.2d) states the relationship between $g_{t}^{*}$ and the revisions.

\subsection{Estimation difficulties with period T-vintage data}

Suppose an econometrician uses the most recent data releases to estimate equations (4.1a) and $(4.1 b)$ by OLS. Often these data are referred to as "final, revised data"; but since the data continue to be revised, we refer to these data as period T-vintage data on $Y_{t}^{T}$. Using the revised data $Y_{t}^{T}$ in place of $Y_{t}^{t}$ and $Y_{t}^{*}$, the system of equations becomes

$$
\begin{aligned}
F F_{t} & =A_{F F}(L) F F_{t-1}+A_{Y}(L) Y_{t-1}^{T}+a_{Y} Y_{t}^{T}+w_{1 t}^{T} \\
Y_{t}^{T} & =B_{F F}(L) F F_{t-1}+B_{Y}(L) Y_{t-1}^{T}+w_{2 t}^{T}
\end{aligned}
$$

The critical questions revolve around the correlation structure of the error terms $w_{1 t}^{T}$ and $w_{2 t}^{T}$ and their relationship to $\varepsilon_{1 t}$ and $\varepsilon_{2 t} .{ }^{10}$ Given the revision process and the true laws of motion, it can be shown that

$$
\begin{aligned}
w_{1 t}^{T} & =\varepsilon_{1 t}-a_{Y} \sum_{s=1}^{T-t} h_{t}^{t+s}-A_{Y}(L) \sum_{s=1}^{T-t} h_{t-1}^{t+s} \\
w_{2 t}^{T} & =\varepsilon_{2 t}-h_{t}^{T *}+B_{Y}(L) h_{t-1}^{T *}
\end{aligned}
$$

\footnotetext{
${ }^{10}$ See Rudebusch (1999) for a discussion of these issues with respect to the monetary policy equation.
} 
When the econometrician estimates equations (4.3a) and (4.3b) with OLS, the estimated regression coefficients are likely to be biased. In general, the error terms $w_{1 t}^{T}$ and $w_{2 t}^{T}$ are correlated with the regressors in both equations. Note that $w_{1 t}^{T}$ contains revisions to date $t$ variables, date $t-1$ variables, and so on, which are correlated with the right-hand-side variables in equation $(4.3 a), Y_{t}^{T}$ and $Y_{t-j}^{T}, j=1,2, \ldots$, except under special assumptions. Similarly, $w_{2 t}^{T}$ contains measurement wedges - differences between the latest measure of the variable and its latent value - which will in general be correlated with the right-hand variables in equation $(4.3 b)$.

The bias to OLS estimators, and the possibility of using alternative estimation methods, depends on the manner in which the data are constructed. Polar cases of data construction include: (1) methods by which revisions to data incorporate news, which is the case when the data agency uses all available data (not just its own sample measuring the data in question) to construct an optimal estimate of the data series in question; and (2) classical measurement error, in which revisions to the data reduce noise, which is the case when the data agency draws an unbiased sample, uses only that sample in constructing its data series, but fails to account for correlations between its data series and other data (not included in its sample) that are available at the time. Of course, data reporting agencies do not directly state which category their reporting method belongs to. Key tests of the extent to which data represent noise or news were undertaken by Mankiw, Runkle, and Shapiro (1984) and by Mankiw and Shapiro (1986). Conditional on the outcome of tests like these, consistent estimators for the parameters in equations (4.3a) and (4.3b) may be apparent. Clearly, the consistency of these estimates will also depend on the validity of the auxiliary assumptions about the data revision process.

\subsection{Using real-time data to estimate the real-time policy equation}

Suppose that the econometrician has the original data for each period, as it was initially released and subsequently revised. For the monetary policy reaction $(4.1 a)$,

$$
F F_{t}=A_{F F}(L) F F_{t-1}+A_{Y}(L) Y_{t-1}^{t}+a_{Y} Y_{t}^{t}+\varepsilon_{1 t}
$$


the econometrician can estimate this equation precisely with the vintage data $\left\{Y_{t-s}^{t}, s \geq 0\right\}$. $O L S$ is consistent, and the exogenous monetary policy shock $\varepsilon_{1 t}$ can be recovered without being polluted by data revisions.

\subsection{Using different data vintages as instruments}

A major stumbling block in estimating equation (4.3b) is that true output $Y_{t}^{*}$ is never fully revealed in the period T-vintage revisions. The error term $w_{2 t}^{T}$ includes the wedge terms $h_{t}^{T *}$. If instead $Y_{t}^{T}$ were to reveal $Y_{t}^{*}$ for some $T$ sufficiently large relative to $t$, then the measurement errors $h_{t}^{T *}$ would disappear from $w_{2 t}^{T}$ completely. In that case, $O L S$ estimation on the output autoregression would recover the true parameters asymptotically as well as the exogenous shocks.

Of course, data revisions never come to a final conclusion. For example, even though no new source data is being collected for 1959 real GDP, those data do get revised periodically. Specifically, when the base year is changed, or the concept is altered (usually slightly), there are data revisions. But it seems plausible to assume that there is some date beyond which all the data revisions are insubstantial. That is, real GDP continues to be revised substantially as new income tax information comes in over the years. Also, seasonal adjustment procedures continue to alter the stochastic seasonals for many years (at least six years). But beyond some threshold, it seems reasonable to assume that the adjustments are completely random (and hopefully small) with respect to previous years of benchmark revisions. Within a benchmark revision, however, the measurement errors may be serially correlated due to interpolation and spreading of annual source data information to quarterly measures.

This discussion is intended to motivate the following statistical model of benchmark data revisions:

$$
Y_{t}^{t+s}=Y_{t}^{*}-\eta_{t}^{t+s}, \quad s \geq J
$$

After the threshold $J$ periods have elapsed, the reported data $Y_{t}^{t+s}$ measure the true $Y_{t}^{*}$ up to a measurement error $-\eta_{t}^{t+s}$ which is independent of $Y^{*}$ and $\eta_{t}^{t+s^{\prime}}$ (where $s^{\prime} \neq s$ ). This model of benchmark revisions allows us to construct an instrumental variables estimator for the output equation (4.3b). In the period T-vintage data, let's restrict the sample period to 
the $Y^{T}$ observations with $\eta^{T}$ measurement errors, so that the error term $w_{2 t}^{T}$ is

$$
\begin{aligned}
w_{2 t}^{T} & =\varepsilon_{2 t}-h_{t}^{T *}+B_{Y}(L) h_{t-1}^{T *} \\
& =\varepsilon_{2 t}-\eta_{t}^{T}+B_{Y}(L) \eta_{t-1}^{T}, \quad t \leq T-J
\end{aligned}
$$

In this part of the sample, $\eta_{t-s}^{T}$ revisions are correlated with $Y_{t-s}^{T}$ and the standard measurement error bias result obtains. However, the $\eta_{t-s}^{T}$ are orthogonal to $Y_{t-s}^{*}$, and hence the earlier vintage errors embedded in $F F_{t-j}$ from the policy reaction function.

Since $F F_{t-1}$ is a valid regressor, an instrumental variables approach only needs to deal with the $Y$ data. To this end, notice that the revision errors $h_{t}^{T *}$ are orthogonal to many other revision errors, once enough time has elapsed from the initial release of the data to ensure that all remaining revisions are orthogonal noise (across benchmark revisions). Given the data vintage denoted by $Y^{T}$, select another data vintage $Y^{T^{\prime}}$. The final time period $T^{\prime}<T$, by assumption (just a normalization). In practical terms, $Y^{T}$ and $Y^{T^{\prime}}$ may be the March 1998 and March 1996 releases of the Citibank data, respectively. Let the estimation period range from observations 1 to $T^{\prime}-J$; this means that all of the data have entered the stage of independent benchmark errors. Consequently, $Y_{t-s}^{T^{\prime}}$ is a valid instrument for $Y_{t-s}^{T}$. That is,

$$
E\left[Y_{t-s}^{T^{\prime}} w_{2 t}^{T}\right]=E\left[Y_{t-s}^{T^{\prime}}\left(\varepsilon_{2 t}-\eta_{t}^{T}+B_{Y}(L) \eta_{t-1}^{T}\right)\right]=0
$$

These orthogonality conditions imply consistent estimation of the parameters in the output equation (4.3b). ${ }^{11}$ Given consistent parameter estimates, the two data vintages yield two residuals $w_{2 t}^{T}$ and $w_{2 t}^{T^{\prime}}$ which are error-ridden measures of the output shock $\varepsilon_{2 t}$. However, the errors are independent of each other. The variance of $\varepsilon_{2 t}$ can be estimated by the sample covariance of these two residuals, and instrumental variables methods can be used to construct impulse response functions.

\footnotetext{
${ }^{11}$ This model of benchmark revisions does have testable restrictions, although the serial correlation in $\eta^{T}$ and $\eta^{T^{\prime}}$ limits the number. From equation (4.4), the cross-covariances of $Y_{t}^{T} Y_{t-j}^{T^{\prime}}$ and $Y_{t-j}^{T} Y_{t}^{T^{\prime}}$ should be equal. We estimated four covariances using generalized method of moments with eight moment conditions, in log levels and again in growth rates. No evidence against these restrictions was found for each of the variables in our VAR which are subject to revision, $(Y, P, N B R, T R)$.
} 


\subsection{Computing impulse response functions}

Given the parameters in equations $(4.1 a)$ and $(4.1 b)$, it is natural to compute impulse response functions from one-time exogenous shocks $\varepsilon_{1 t}$ and $\varepsilon_{2 t}$ at time $t$ to the paths of $\left\{F F_{t+j}, Y_{t}^{t+j}, Y_{t+j}^{*}\right\}$ for all $j \geq 0$. The data revision process complicates these calculations: at time $t$, the policy reaction function responds to the initially reported data $Y_{t}^{t}$ and its revisions to previously released data $Y_{t-s}^{t}$. Consequently, the response of data revisions to the exogenous shocks must be known in order to compute the response of $F F$.

Recall that the revision process follows

$$
\begin{aligned}
Y_{t}^{t} & =Y_{t}^{*}-h_{t}^{t+1}-h_{t}^{t+2}-\ldots-h_{t}^{T}-h_{t}^{T *} \\
h_{t}^{t+s} & =Y_{t}^{t+s}-Y_{t}^{t+s-1}, \quad \forall s \geq 1, \quad \forall t .
\end{aligned}
$$

Several observations are in order. First, the revision process $h_{t}^{t+s}$ is an observable data series for each $s \geq 1$. The $s$-revision $h_{t}^{t+s}$ is assumed to be a stationary process and has a Wold representation which is a function of the exogenous shocks $\varepsilon_{1 t}$ and $\varepsilon_{2 t}$, as well as its own shock. The response of $h_{t}^{t+s}$ to the exogenous policy shock $\varepsilon_{1 t}$ can be estimated by $O L S$ as

$$
h_{t}^{t+s}=\psi_{1 s}(L) \varepsilon_{1 t+s}+\omega_{1 t+s \mid t}
$$

where $\omega_{1 t+s \mid t}$ is a serially correlated random variable comprised of the other shocks. ${ }^{12}$ Without placing additional structure on the measurement problem, it is not possible to rule out the effect of $\varepsilon_{1 t+s}$ on $h_{t}^{t+s}$ even though $Y_{t}^{*}$ was clearly unaffected. If the statistical agency is solving a statistical signal extraction problem with the Kalman filter (as in Sargent (1989)), then future values $Y_{t+s}^{*}$ provide information on the unobserved $Y_{t}^{*}$. Alternatively, if the statistical agency simply receives more accurate measurements of $Y_{t}^{*}$, then only $\varepsilon_{1 t}$ and its history will influence $h_{t}^{t+s}$. And given the recursive orthogonalization in equation (4.1a), the contemporaneous value $\varepsilon_{1 t}$ will not influence the revision either. In the empirical analysis

\footnotetext{
${ }^{12}$ The regular calendar of benchmark revisions may lead to seasonal periodicities in these responses. We have included seasonal dummy variables in our estimation of the revision responses to minimize these influences.
} 
below, we adopt this latter interpretation of the statistical agency's approach to computing revisions. Second, the counterpart to equation (4.6) for the other exogenous shock $\varepsilon_{2 t}$ is

$$
h_{t}^{t+s}=\psi_{2 s}(L) \varepsilon_{2 t+s}+\omega_{2 t+s \mid t} .
$$

The difficulty in estimating the responses $\psi_{2 s}(L)$ is the lack of data for $\varepsilon_{2 t}$; instead, only the error-ridden measures $w_{2 t}^{T}$ and $w_{2 t}^{T^{\prime}}$ are available. However, the noises in $w_{2 t}^{T}$ and $w_{2 t}^{T^{\prime}}$ are uncorrelated, so $\psi_{2 s}(L)$ can be estimated by instrumental variables. Third, computing the accumulation of future $s$-revisions in $Y_{t}^{t}$ is straightforward given estimates of $\psi_{1 s}(L)$ and $\psi_{2 s}(L)$. Finally, since $h_{t}^{T *}$ is the permanent wedge between $Y_{t}^{*}$ and its eventual measurement, it is not observed. We assume that $h_{t}^{T *}$ is unaffected by the exogenous shocks, so that its response is zero.

To summarize, the availability of the stationary $s$-revisions $h_{t}^{t+s}$ allows direct estimation of their response to exogenous shocks. By knowing all of the conditional responses, the cumulative effect in the initial release $Y_{t}^{t}$ can be computed. To compute the full-system impulse responses, we need only add these recursions to the system of equations.

\section{Empirical results with real-time data VAR}

To investigate the implications of using real-time data in a VAR, we estimate the 6-variable $C E E$ system described in Section 3. We use the Croushore-Stark real-time data set. The variables are real $G D P(Y)$, the implicit $G D P$ deflator $(P)$, an index of commodity prices $(P C O M)$, the federal funds rate $(F F)$, nonborrowed reserves $(N B R)$, and total reserves $(T R)$. The data are in logs, except for $F F$. The two data vintages to be used as instruments for the latent variables are $T^{\prime}=1996: 3$ and $T=1998: 3$. We take the benchmark threshold $J=12$ quarters, so our estimation period runs from 1968:1 through 1993:3. As described in Section 4, the federal funds rate equation is estimated with real-time data (equation 4.1a), while the other equations are specified as latent variables (similar to equation 4.1b specified for a vector of data). The order of orthogonalization for studying nonpolicy shocks 
is $Y, P, P C O M, F F, N B R, T R .^{13}$

Figure 5.1 displays the estimated $F F$ policy shock using real-time data and an $F F$ policy shock estimated from the fixed 1998:3-vintage data set (as a typical VAR is estimated). Overall, the series are remarkably similar. The correlation over the full-sample period is 0.89 , and 0.74 over the more recent period 1987-93. The standard deviations of the two shocks are 75 and 87 basis points for the real-time and 1998:3-vintage data measures, respectively. Nevertheless, there are some notable differences. First, in the third and fourth quarters of 1974, the 1998:3-vintage data overstates the volatility of exogenous monetary policy, relative to the VAR's data available to policymakers. Romer and Romer (1989) selected April 1974 as a date when the Federal Reserve explicitly chose to sacrifice output in order to bring an exogenous burst of inflation down. The real-time VAR residuals indicate that this was a period when the FOMC was responding in a rather typical fashion to the data they were given. Second, the three large contractionary shocks in 1980:4, 1981:2, and 1982:1 are overstated in the 1998:3 vintage data by 120, 60, and 70 basis points, respectively, when compared with the available VAR data the FOMC had access to. Third, the two series appear to become less contemporaneously aligned since the stock market decline in 1987. The real-time exogenous tightening in 1988 leads the 1998:3 vintage by a quarter throughout the year, and the subsequent exogenous easing through 1989 is similarly misaligned. In spite of this, the general assessment of exogenous monetary policy as being tight or loose over the course of a four quarter period will not differ appreciably across these two measures. ${ }^{14}$

Figure 5.2 displays the impulse responses from the FF shock for the estimated realtime system and the 1998:3 vintage estimates. Again, the similarity across the two systems is striking. Relative to the 1998:3 vintage estimates, the real-time $F F$ response displays slightly less persistence. The real-time output price and commodity price responses are a bit shallower than the revised data estimates. Although confidence intervals have not been

\footnotetext{
${ }^{13}$ The contemporaneous terms in the multivariate counterparts to $4.1 \mathrm{a}$ and $4.1 \mathrm{~b}$ are treated in the standard way. We have also estimated the $P C O M$ equations using real-time data by $O L S$. Those results are similar to the ones reported below.

${ }^{14}$ Rudebusch (1999) finds that $F F$ residuals from a monthly VAR are quite different from forecast errors inferred from the Federal funds futures market over the period 1989-1996. In addition to the difference in information sets across the two analyses, futures market participants do not necessarily presume that monetary policy follows a linear, time-invariant feedback rule. Consequently, evidence from futures market data do not directly shed light on the effect of real-time data for VAR policy shock measures.
} 
computed, the broad similarity of the responses and the typical confidence band width provides little evidence that the monetary policy shock VAR literature has been misled by its use of "final, revised data" to date. This tentative conclusion does not mean necessarily that revisions are small in the data. Figure 5.3 displays the revision responses to the real-time policy shock. The dashed lines indicate the various vintages $t+s$ of time $t$ data that are reported following a shock. For example, in the first row of column one, the response of $Y_{t}^{t}$ over 32 quarters is displayed, and the second and third quarters are reported as more negative than the true, latent $Y_{t}^{*}$. The initial step is zero due to the order of orthogonalization. The second row shows that the first revision $Y_{t}^{t+1}$ moves closer to the true path, but is still more negative initially. This pattern would contribute to a less persistent $F F$ response, since the reported output data weakens more quickly than true economic activity. ${ }^{15}$ The other data exhibit similar deviations of the measured series from the true variable, although the scale in the figures makes this less apparent. Nevertheless, the empirical finding is that accounting for data revisions in the real-time policy rule does not alter our assessment of the VAR monetary policy evidence.

Figure 5.4 displays the system's response from an exogenous shock to true output $Y_{t}^{*}$. Except for the commodity price and deflator paths after 3 and 5 years, respectively, the responses are quite similar across estimation methods. Qualitatively similar observations apply for the $P^{*}$ and $P C O M^{*}$ shocks displayed in Figures 5.5 and 5.6: The divergence seems largest for commodity prices and the deflator rather than the other variables, and after 3 to 5 years at that. The response of $Y^{*}$ from the $P C O M^{*}$ shock is an exception, in Figure 5.6. One possibility is that the real-time data estimation is more closely estimating a unit root for the price variables, than for the revised vintage data. This requires more exploration.

\section{Conclusions}

Empirical VAR research often ignores issues associated with data revisions and economic agents' access to only real-time data releases. Since government agencies and private sources

\footnotetext{
${ }^{15}$ In these results, we only use four revision periods, $h_{t}^{t+1}$ through $h_{t}^{t+4}$ to estimate the response to shocks. This means that after four periods, only the wedge $h_{t}^{T *}$ remains between $Y_{t}^{t+4}$ and $Y_{t}^{*}$, and that is unaffected by the shocks (by assumption).
} 
do not provide these data conveniently, these shortcuts are rarely questioned. The real-time data collected by Croushore and Stark (1999) allows researchers to explore the empirical robustness of many existing macroeconomic results to this issue, but additional structure must be placed on the data revision process and assumptions about regarding the information that economic agents have access to. Our empirical analysis indicates that accounting for data revisions has only a modest effect quantitatively on the monetary policy shock measures and impulse responses we consider. All of our results are conditional on our assumptions about data revisions and the latent structure of the economy. More research that allows for

alternative measurement noise and data revision processes is needed to shed more light on the role of data revisions.

\section{References}

[1] Bernanke, Ben and Alan Blinder, 1992, "The federal funds rate and the channels of monetary transmission," American Economic Review 82: pp. 901-21.

[2] Bernanke, Ben and Ilian Mihov, 1998, "Measuring Monetary Policy," Quarterly Journal of Economics 113 (August): pp. 869-902.

[3] Blanchard, Olivier Jean, and Danny Quah. "The Dynamic Effects of Aggregate Demand and Supply Disturbances." American Economic Review 79 (September 1989), pp. 65573.

[4] Christiano, Lawrence, Martin Eichenbaum and Charles L. Evans, 1996, "The effects of monetary policy shocks: evidence from the flow of funds," Review of Economics and Statistics 78 (February 1996): pp. 16-34.

[5] Christiano, Lawrence, Martin Eichenbaum and Charles L. Evans, 1999, "Monetary policy shocks: what have we learned and to what end?" Forthcoming in the Handbook of Macroeconomics. 
[6] Croushore, Dean, and Tom Stark. "A Real-Time Data Set for Macroeconomists: Does the Data Vintage Matter?" Federal Reserve Bank of Philadelphia working paper 99-21, December 1999.

[7] Diebold, Francis X. and Glenn D. Rudebusch. "Forecasting Output with the Composite Leading Index: A Real-Time Analysis." Journal of the American Statistical Association 86 (September 1991): pp. 603-10.

[8] Galí, Jordi. "How Well Does the IS-LM Model Fit Postwar U.S. Data?" Quarterly Journal of Economics (May 1992), pp. 709-38.

[9] Hall, Robert E. "Stochastic Implications of the Life Cycle-Permanent Income Hypothesis: Theory and Evidence," Journal of Political Economy 86 (December 1978), pp. 971-87.

[10] Leeper, Eric, Christopher Sims, and Tao Zha, 1997, "What does monetary policy do?" Brooking Panel on Economic Activity.

[11] Mankiw, N. Gregory, David E. Runkle, and Matthew D. Shapiro. "Are Preliminary Announcements of the Money Stock Rational Forecasts?" Journal of Monetary Economics 14 (July 1984), pp. 15-27.

[12] Mankiw, N. Gregory, and Matthew D. Shapiro. "News or Noise: An Analysis of GNP Revisions," Survey of Current Business (May 1986), pp. 20-5.

[13] Orphanides, Anthanasios, 1998, "Monetary policy rules based on real-time data," Board of Governors, FEDS working paper 1998-03.

[14] Rudebusch, Glenn D. "Do Measures of Monetary Policy in a VAR Make Sense?" International Economic Review 39 (November 1998), pp. 907-31.

[15] Sargent, Thomas 1989, "Two models of measurements and the investment accelerator," Journal of Political Economy 97: pp. 251-87. 
[16] Sargent, Thomas and Christopher Sims, 1977, "Business cycle modeling without pretending to have too much a priori economic theory," Christopher Sims (ed.), New Methods in Business Cycle Research, Federal Reserve Bank of Minneapolis.

[17] Sims, Christopher, 1992, "Interpreting the macroeconomic time series facts: the effects of monetary policy," European Economic Review 36: pp. 975-1011.

[18] Sims, Christopher and Tao Zha, 1996, "Does Monetary Policy Generate Recessions?" unpublished manuscript.

[19] Stock, James and Mark Watson, 1989, "New indexes of coincident and leading economic indicators," NBER Macro Annual 4, MIT Press. 
Figure 3.1

CEE Model Monetary Policy Shocks

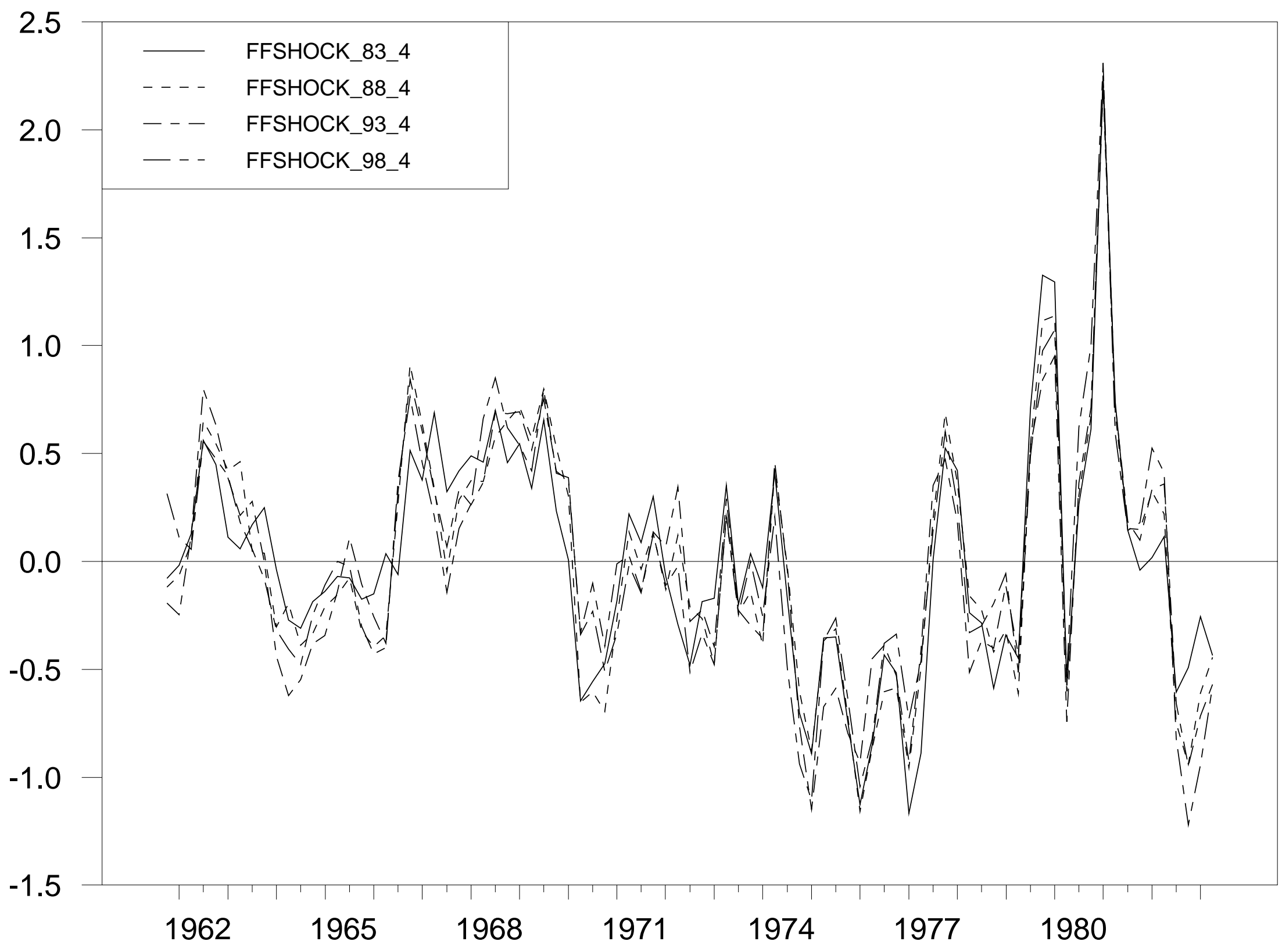




\section{Figure 3.2}

CEE Model Impulse Responses to Monetary Policy Shock
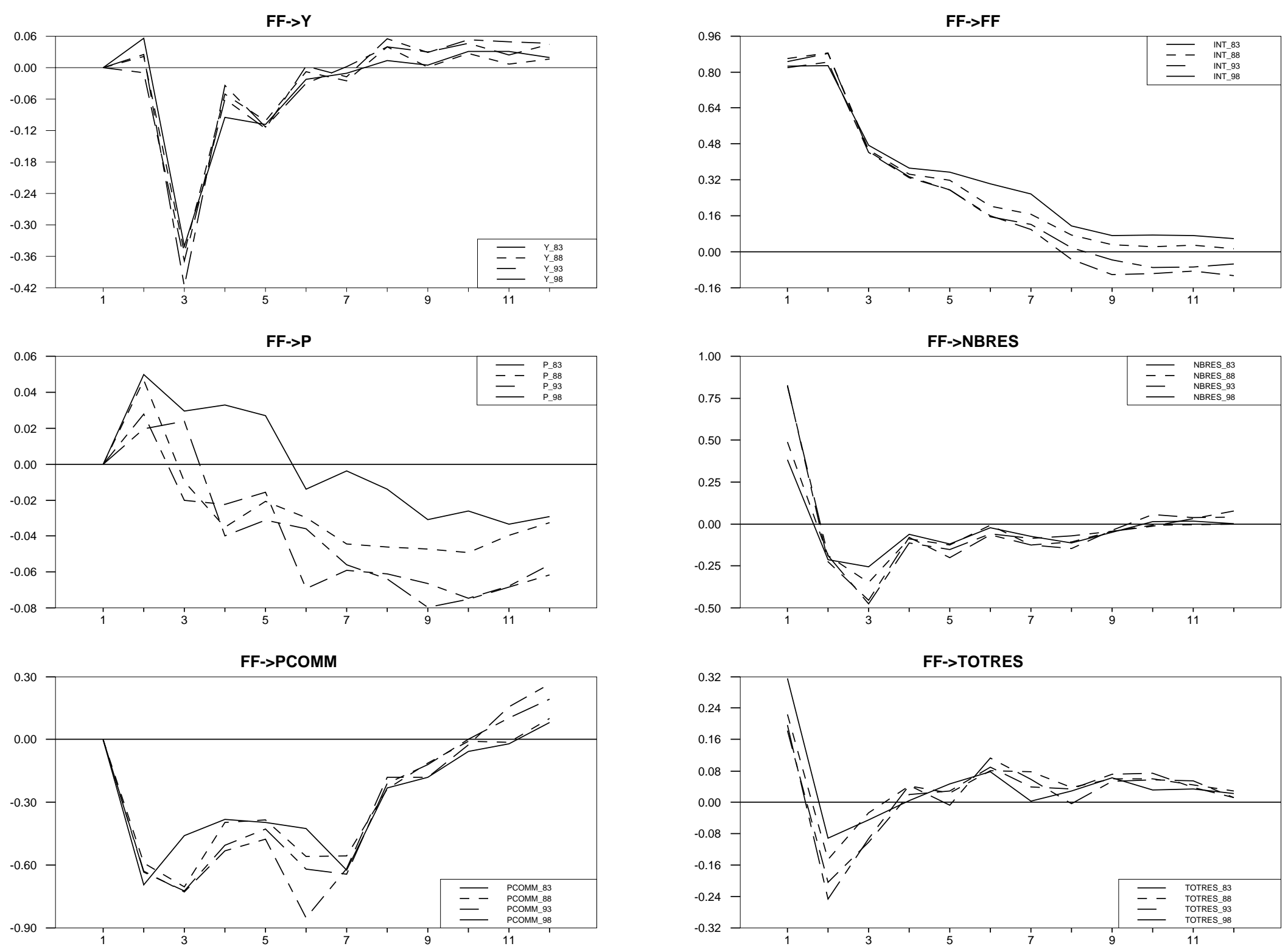
Figure 3.3

Gali Model Monetary Policy Shocks

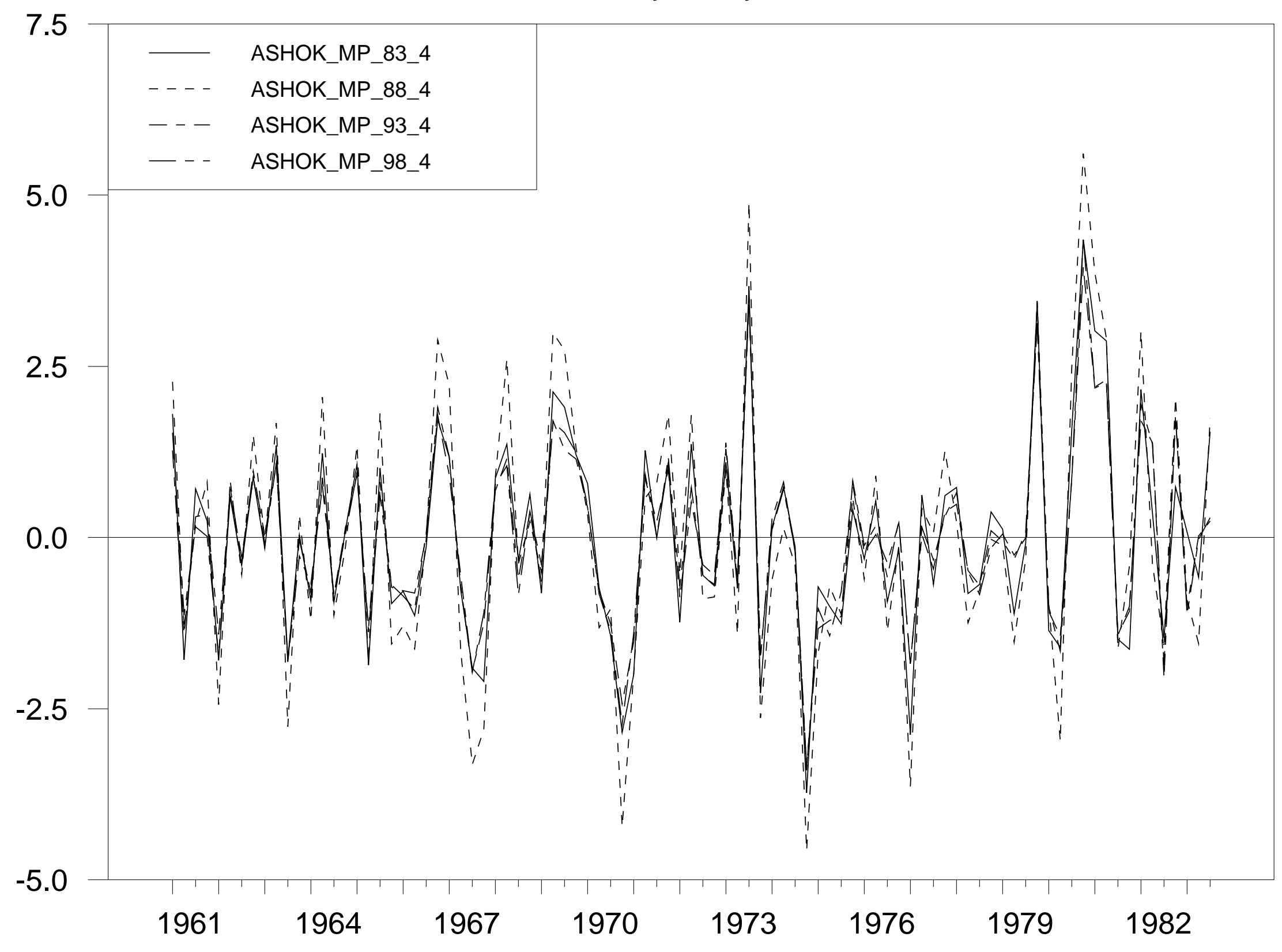




\section{Figure 3.4}

Gali Model Impulse Responses to Monetary Policy Shock
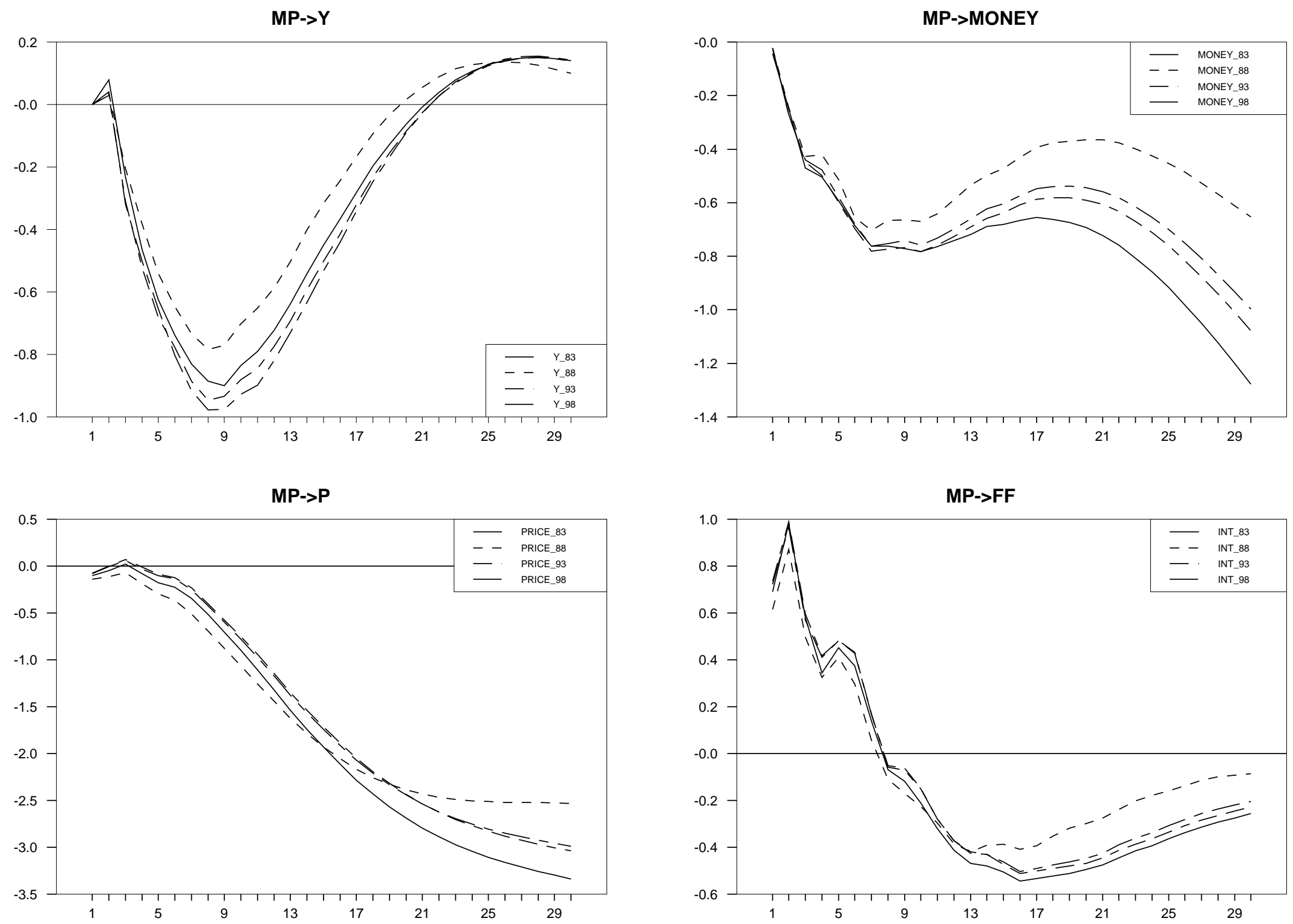
Flgure 5.1

\section{Real-time MP shocks v. 1998 vintage shocks}

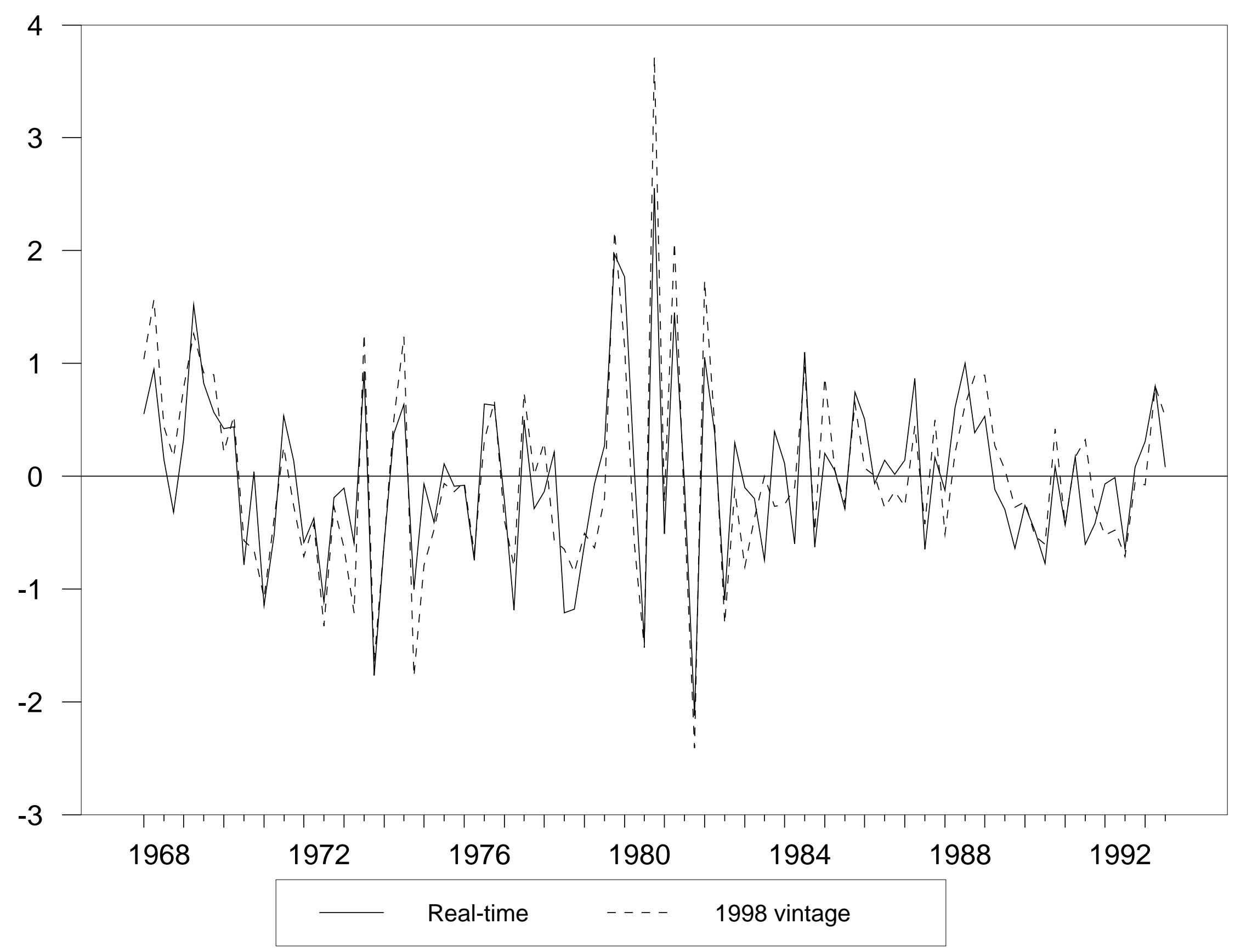


Figure 5.2

\section{Real-time v. 1998 vintage: 1968-93}

\section{Y-P-PCOM-FF-NBR-TR}
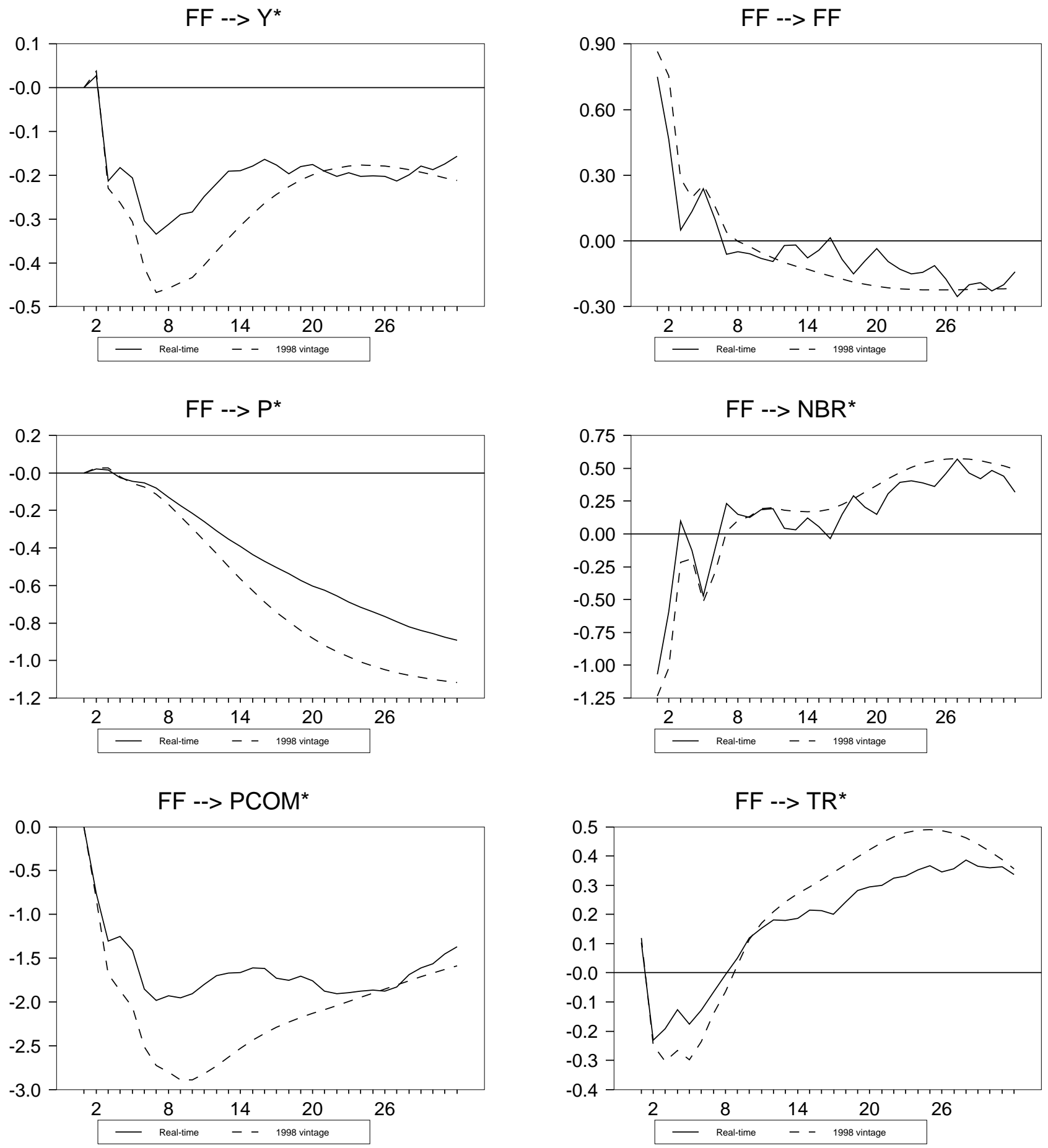
Figure 5.3

\section{Data revisions after FF shock(1968-93)}

Y-P-PCOM-FF-NBR-TR
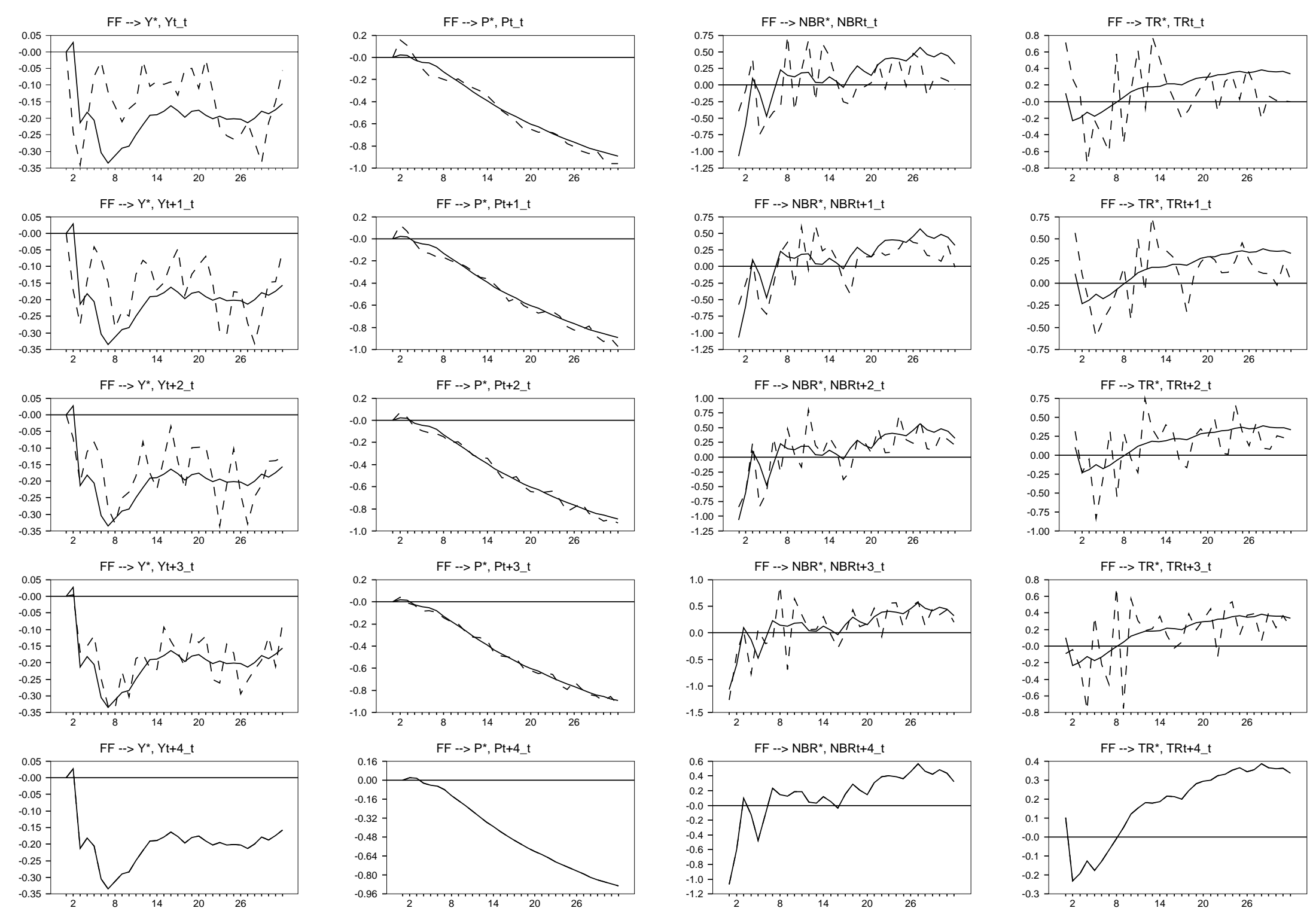
Figure 5.4

\section{Real-time v. 1998 vintage: 1968-93}

\section{Y-P-PCOM-FF-NBR-TR}
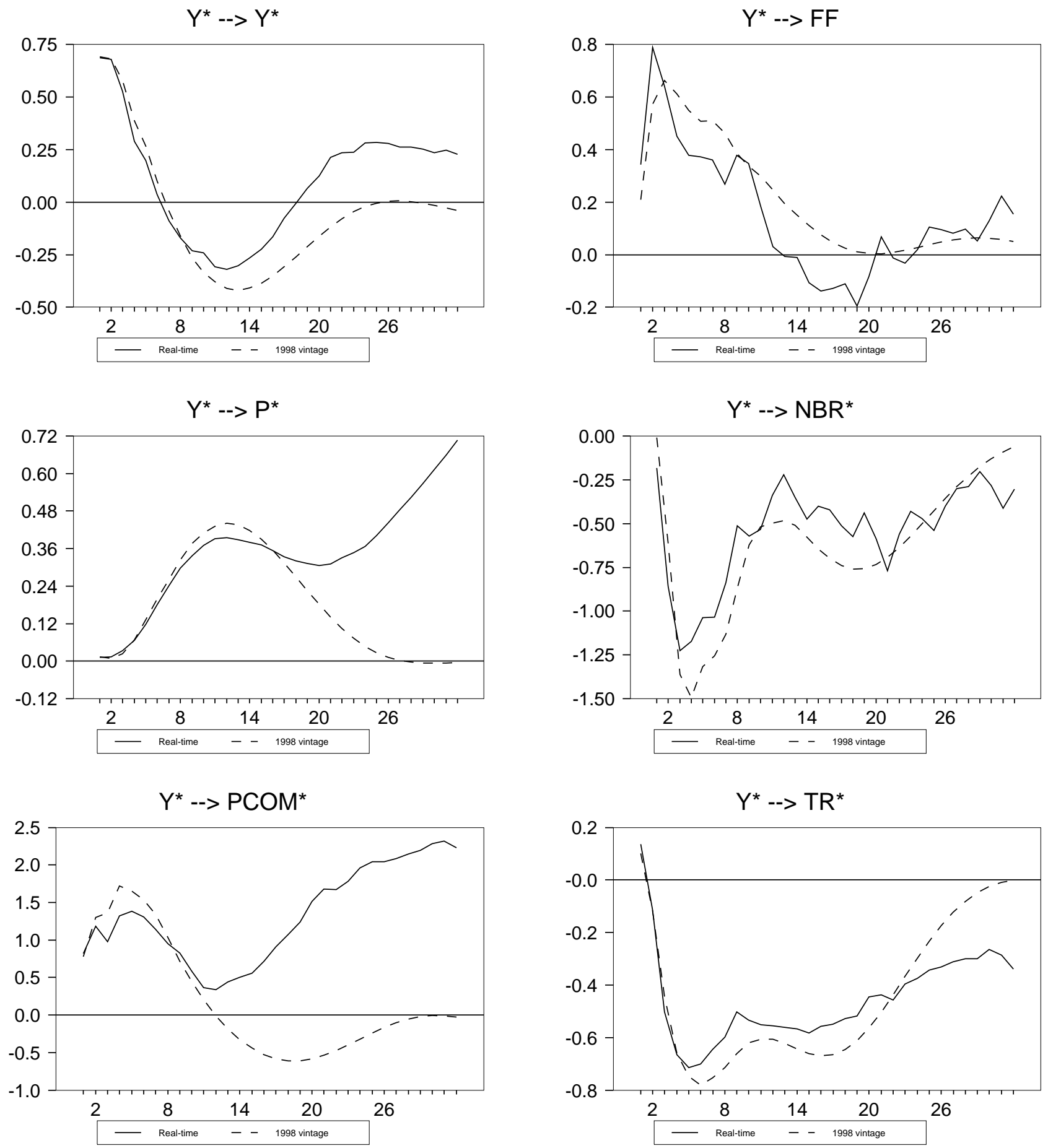
Figure 5.5

\section{Real-time v. 1998 vintage: 1968-93}

\section{$Y-P-P C O M-F F-N B R-T R$}
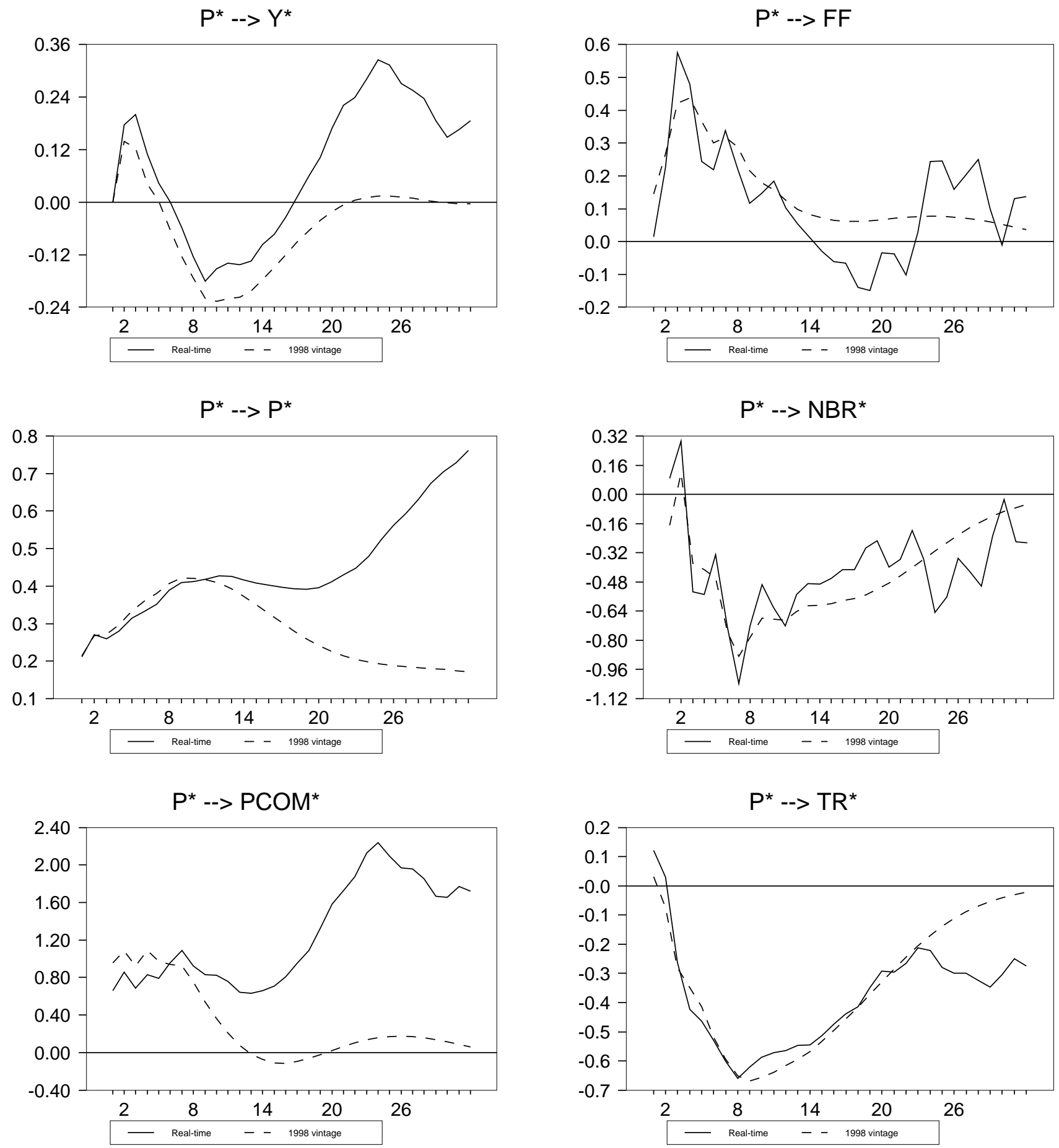
Figure 5.6

\section{Real-time v. 1998 vintage: 1968-93}

\section{$Y-P-P C O M-F F-N B R-T R$}
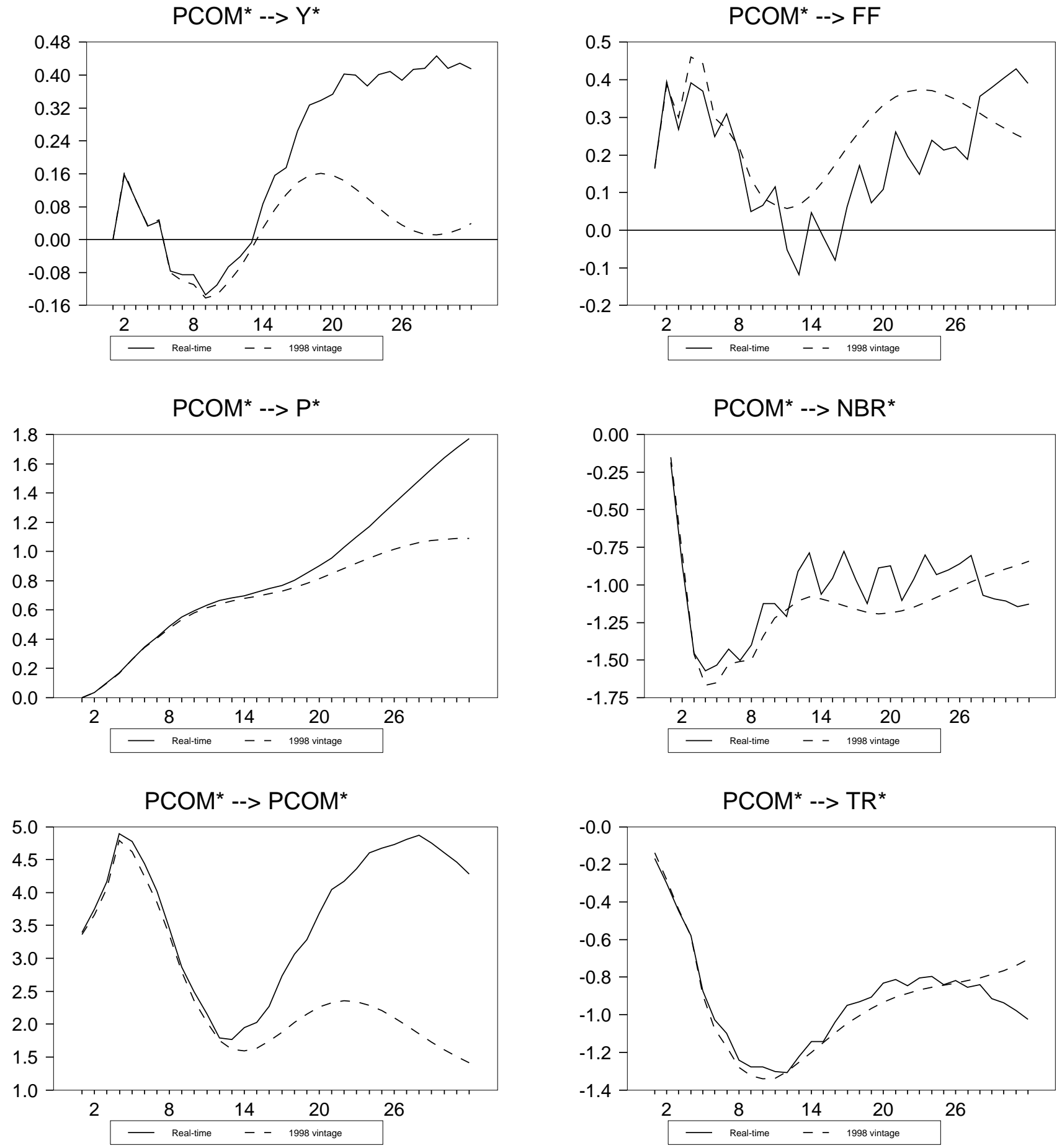